\title{
Hacia una antropología hermenéutica del sufrimiento. Fenomenología de la acción (y del sufrir), ética de la resistencia y hermenéutica de la parsimonia. (Una presentación de El sufrimiento no es el dolor de Paul Ricœur)
} Towards a Hermeneutical Anthropology of Suffering. Phenomenology of Action (and of Suffering), Ethics of Resistance and Hermeneutics of Parsimony. (A presentation of Suffering is not pain, by Paul Ricœur)

\author{
TOMÁs Domingo Moratalla* \\ UNED. Facultad de Filosofía
}

\begin{abstract}
RESUMEN. Presento en este texto el artículo de P. Ricœur El sufrimiento no es el dolor. Tras contextualizarlo paso a indicar cuáles son sus temas vertebradores para después, en un segundo momento, indicar su relevancia y trascendencia. Se trata de un trabajo muy importante en la trayectoria del pensador francés, pues nos permite entender mejor su propuesta de fenomenología hermenéutica, así como su dimensión ética. Además, la antropología del sufrimiento que nos ofrece permite vertebrar las líneas fundamentales de una ética (y política) del cuidado -sugerente, actual y llena de posibilidades.
\end{abstract}

Palabras clave: Ricœur; sufrimiento; fenomenología; hermenéutica; ética del cuidado.
ABSTRACT. I present in this text the article by P. Ricœur Suffering is not pain. After contextualizing it, I will indicate what are its backbone themes and then, in a second moment, indicate its relevance and significance. This is a very important work in the career of the French thinker, because it allows us to better understand his proposal of hermeneutical phenomenology, as well as its ethical dimension. In addition, he offers an anthropology of suffering that allows us to structure the fundamental lines of an ethic (and politics) of care-fearful, current and full of possibilities.

Key words: Ricœur; Suffering; Phenomenology; Hermeneutics; Ethics of Care.

\footnotetext{
*tdmoratalla@ffsof.uned.es ORCID iD: https://orcid.org/0000-0002-3237-9540. Profesor de Antropología Filosófica. UNED. Facultad de Filosofía. Madrid. Correspondant FONDS-Ricoeur (España). Presidente de la Sociedad Hispánica de Antropología Filosófica.
} 
Una sencilla frase da título al texto: el sufrimiento no es el dolor. El sufrimiento no es sólo dolor, aunque también lo sea. Pensar la experiencia que sustenta esta afirmación es la propuesta que nos hace Paul Ricœur. Nada más y nada menos. Ahora bien, pensar con radicalidad esta experiencia compleja nos lleva a subvertir el orden de los discursos y el orden de las prácticas.

Ricœur nos ofrece aquí un pequeño texto que bien podemos calificar, sin exageración, de extraordinario, pleno de sutileza y finura; un texto sin concesiones académicas o estilísticas; denso, difícil y, al mismo tiempo, magnífico. Muchas veces Ricœur adopta en sus escritos un tono expositivo, claro, incluso diáfano; esto ocurre tras tratar un tema después de amplios recorridos conceptuales o cuando se dedica a introducirnos en una cuestión o a cerrar un debate. No es este el caso. No es un texto cualquiera del pensador francés. Se trata de uno de esos textos, uno de esos momentos, donde él mismo se expone; está pensando, está siendo obligado a pensar y da que pensar. Y por eso mismo resulta magnífico. Estas pocas páginas, además, esconden dentro de sí todo un programa de investigación y son, también, paradigma de un modo de hacer filosofía: una fenomenología que mira a la hermenéutica y a las ciencias, y que tiene una clara vocación práctica. Es un texto vivo; utilizando una expresión del propio Ricœur en el texto llegaría a hablar de herida viva.

Este pequeño texto es muy valioso, y lo es porque nos brinda recursos conceptuales de especial importancia para pensar el dolor y el sufrimiento, sin juzgarlos con precipitación, sino buscando la claridad. Son temas en los que se tiende a la confusión, al dolorismo, al silencio o al grito, a la tragedia o a la banalidad. Ricœur introduce la calma necesaria en la reflexión, es decir, parsimonia, y de esta manera subvierte la cuestión, "nos da que pensar" (y hacer).

Vemos también que es un texto que pide prolongaciones, pues necesariamente tiene que resonar en los diferentes ámbitos afectados: médicos, personal sanitario en general, psicólogos, sociólogos, filósofos, etc., e incluso en todos, nos afecta a todos. Más allá de las prolongaciones posibles del texto, tiene un especial interés la aplicación que se puede hacer en el ámbito de los cuidados paliativos o en el difícil tema del final de la vida. ${ }^{1}$

${ }^{1}$ Ejemplo de una prolongación, contextualización y desarrollo de estas ideas es el Congreso organizado en Valencia (2013) y que recoge a propósito de estos temas numerosas aportaciones de algunos de los mayores expertos del pensamiento de Ricœur. Cfr. T. Domingo Moratalla, A. Domingo Moratalla, Bioética y hermenéutica. La ética deliberativa de Paul Ricœur (Actas del Congreso Internacional, Valencia, España, febrero 2013), Editorial Hermes, Valencia, 2014, pp. 429. Por mi parte he intentado sistematizar la aportación de Ricœur al ámbito de la bioética (ética médica) en "Bioética y hermenéutica. La aportación de Paul Ricœur a la bioética”, Veritas, vol. II, nº 17, 2007, pp. 281-312. Tantos las actas como este artículo están disponibles electrónicamente. 
La reflexión que se lleva a cabo es muy actual y necesaria; lo que pretendemos no es recuperar académicamente un texto más o menos curioso o interesante. Es un texto para pensar con radicalidad, para vivirlo en su profundidad. Además, no es un texto que haya envejecido, al contrario. ${ }^{2}$ Nos ofrece claves conceptuales de las que carecemos para pensar los polifacéticos rostros del sufrimiento, las múltiples violencias que podemos sufrir, y las múltiples dificultades para atender el sufrimiento.

\section{EL TEXTO Y SUCONTEXTO}

El texto procede de una conferencia y mantiene ese tono de conferencia, de sugerencia, de un pensar en marcha. No está corregido y algún error se desliza, a veces la puntuación es difícil y el ritmo se entrecorta, incluso algún nombre se cambia. Pero merece la pena enfrentarse a él. Nos habla del sufrimiento y del dolor. No nos puede resultar ajeno lo que en él se plantea; y no se limita Ricœur a escribir sobre ello, sino que escribiendo lo vive, vive el sufrimiento. A veces un texto es también un trabajo de duelo, eso sucede aquí; aun así, siendo apasionado, no deja de ser tremendamente iluminador, esclarecedor.

El texto procede de una intervención en el Coloquio "El psiquiatra ante el sufrimiento", organizado por la Asociación Francesa de Psiquiatría en Brest, los días 25 y 26 de enero de 1992. Se publicó en un número especial de la revista Psychiatrie française (junio, 1992), y posteriormente también en un número extraordinario de la revista Autrement titulado "Souffrances". ${ }^{3}$ Muy significativa es la reedición que se hizo en 2013 a propósito de un encuentro, en torno al propio texto, en $2012 .{ }^{4}$ Las distintas versiones publicadas no presentan variaciones del texto.

Ricœur fue invitado a este encuentro por el presidente de la Asociación de Psiquiatría Francesa, Jean-Jacques Kress. Me permito un pequeño comentario que puede ayudar a contextualizar el escrito. Jean-Jacques Kress es un viejo conocido de la familia Ricœur. Cuando Ricœur estuvo en Estrasburgo en los años cincuenta el joven Jean-Jacques visitaba su casa, pues le unía una estre-

${ }^{2}$ En resonancia y prolongación de este planteamiento del sufrimiento, con todo lo que implica, cfr. las propuestas de J. C. Mino (Hors de moi, Allia, Paris, 2008 ; Violences de la maladie, violence de la vie, Armand Colin, Paris, 2008 ;) y de F. Worms (Le moment du soin, À quoi tenons-nous?, PUF, Paris, 2010. Ambos editaron hace unos años una magnífica recopilación de trabajos en esta orientación Ricœuriana (La philosophie du soin. Médecine, éthique, société, PUF, Paris, 2010).

${ }^{3} \mathrm{n}^{\circ} 142$, febrero 1994.

${ }^{4}$ C. Marin, N. Zaccaï-Reyners (eds.), Souffrance et douleur. Autour de Paul Ricour, PUF, Paris, 2013. El texto de Ricœur: pp. 13-33. 
cha amistad con Jean-Paul, hijo mayor de Ricœur, también conocía y trataba a los otros hijos; en otros momentos aparecerá en la vida de Ricœur, como, por ejemplo, en los debates en torno al psicoanálisis. Ahora, en esta invitación en 1992, y a propósito de este tema, vemos a Ricœur debatiéndose con el mayor drama que vivió: el suicidio de su hijo Olivier en 1986. Nos encontramos con un trabajo de duelo. El duelo por la muerte de su hijo recorre el texto, en el late la vivencia más terrible sin dejar de ser al mismo tiempo un trabajo teórico, y de considerable potencia conceptual. Varias veces aparece en el texto la expresión “¿por qué a mí? ¿por qué a mi hijo?”; entiéndase también desde el punto de vista de la vivencia personal. El profesor Jean-Jacques Kress ha recordado en más de una ocasión las palabras de Ricœur cuando decía que para entender la identidad humana, la vida humana, hay que aproximarse a los momentos en que ésta se tambalea (señalaba Ricœur: "Para comprender cómo sucede, es necesario ver cómo se deshace").

\section{GRANDES TEMAS ABORDADOS}

No pretendo ahora un análisis de este espléndido texto, tampoco sustituir su lectura, tan solo, a la vista de su dificultad, ofrecer indicaciones para que el lector pueda orientarse en su discurrir. ¿Qué nos propone? Un análisis del sufrimiento. Recojo de una manera sucinta los temas más importantes.

A manera de preámbulo: Nos quiere ofrecer un análisis de "la experiencia humana más común y más universal del sufrir", con la intención de comprender al ser humano como ser capaz, también capaz de sufrir; para ello se va a mover entre la fenomenología y la clínica, buscando una "inteligencia de los signos del sufrir". Las implicaciones metodológicas son muy importantes.

Punto de partida: En principio se puede distinguir el dolor, como algo puramente físico-orgánico, del sufrimiento como algo reflexivo-subjetivo; la propuesta de Ricœur es cuestionar esta distinción. Ni hay dolor sin sufrimiento, ni sufrimiento sin dolor. ¿Qué es sufrir?

Estrategia: ¿Cómo organizar los "signos del sufrir" para no perderse con los análisis indistintos del sufrir (una fenomenología de la conciencia del sufrir que no sale de sí misma)? Ricœur esboza una hermenéutica del sufrimiento a través de dos ejes fundamentales de análisis, y un tercero que los recorre transversalmente.

1) Eje sí mismo-otro. El sufrimiento puede analizarse y comprenderse en relación con uno mismo y en relación con los otros. Ricœur despliega con finura descriptiva un análisis que va desde el yo entendido como "herida viva" a las múltiples figuras del otro en la experiencia del sufrir.

2) Eje hacer-padecer. Ricœur definió al ser humano en Sí mismo como otro ${ }^{5}$

${ }^{5}$ P. Ricœur, Soi-même comme un autre, Éditions du Seuil, Paris, 1990. 
como ser actuante, agente, y también, sufriente. Ahora recorre la caracterización de las capacidades del 'sí mismo', de la persona, que describió en esta obra, desde el lado del sufrimiento, desde las fragilidades y vulnerabilidades. El sufrimiento es la disminución del 'poder decir', del 'poder hacer', del 'poder narrar' y del poder 'estimarse a sí mismo'.

Y este espacio trazado por ambos ejes, este mapa de comprensión del sufrirpodríamos considerarlo así-, es recorrido transversalmente por un eje cuyo criterio es la expresión del sufrimiento, e iría desde el silencio y la mudez que provoca el sufrir hasta el grito angustiado que reclama ayuda.

En la última parte del trabajo Ricœur se plantea si se puede decir que el sufrimiento enseña, como decía Esquilo y con él toda nuestra tradición occidental. No hablará de "enseñanza del sufrimiento" y prefiere retomar el lema que su hermenéutica ha hecho clásico y así nos dirá que el sufrimiento (como la imaginación, etc.) da que pensar. Huye del dolorismo y del sentimentalismo. El sufrimiento exige hablar con modestia y respeto. El sufrimiento "interroga" (¿por qué es lo que no debería ser?) y el sufrimiento "apela" (por ejemplo, a la "solidaridad de los conmovidos”, como decía J. Patočka).

Concluye recordando que sufrir es también "aguantar" y, sobre todo, perseverar en el deseo de ser y en el esfuerzo por existir, que nos constituye, y ello siempre... a pesar de....

Hasta aquí los grandes temas. Paso a continuación a comentar algunas cuestiones del texto que pueden aportar luz e invitar a la reflexión, sin buscar agotar el análisis.

\section{UN ESTILO Y UNA ORIENTACIÓN: FENOMENOLOGÍA, HERMÉNEUTICA Y ÉTICA}

Este texto es muy importante y significativo también porque nos permite apreciar de una forma condensada y ejemplar la propuesta filosófica general de Ricœur. Nos ofrece brillantes indicaciones sobre la metodología ricœuriana. Este pequeño texto nos ofrece un ejemplo extraordinario de lo que puede ser una fenomenología hermenéutica: el análisis de la experiencia no se reduce a una descripción más o menos intuitiva, más o menos directa, de la propia vivencia, sino que cuenta con indicaciones externas, en este caso cuenta con la nosografía psiquiátrica, con la palabra y el saber de médicos y psiquiatras. El análisis fenomenológico no puede ser nunca un análisis solipsista de la propia vivencia, que podemos creer universal. La fenomenología ha de articularse, necesariamente, con otros saberes, con otras interpretaciones; por eso la fenomenología precisa de la orientación hermenéutica. La fenomenología, sin la mediación hermenéutica (que puede ser de diferente tipo), corre el riesgo de ser un discurso vacío. 
La mejor manera de comprender la filosofía de Ricœur es entendiéndola como una antropología filosófica, la cual no deja de reelaborar para lograr que responda a los retos que nuestro propio tiempo nos plantea. Pero, ¿qué antropología filosófica? Me atrevería a decir que se trata de una antropología filosófica entendida como filosofía primera; los diferentes horizontes filosóficos en los que Ricœur se mueve pueden ser entendidos como despliegue o desarrollos de una filosofía antropológica.

La forma adecuada de constituir esta antropología filosófica es a través de la fenomenología y su versión hermenéutica. Esto lo decimos con respecto a la propuesta programática que nos encontramos en el propio Ricœur o con respecto al estudio de sus grandes temas (mitos, metáfora, tiempo, narración, historia, etc.), pero es en este pequeño artículo donde vemos trazado de una forma paradigmática este entrecruzamiento de fenomenología y hermenéutica, o el injerto de la hermenéutica en la fenomenología o, dicho de otra manera, esta necesidad que tiene la fenomenología de asumir el giro hermenéutico. Además, vemos cómo esta fenomenología hermenéutica ha de contar necesariamente con las aportaciones de otros campos, en concreto con las aportaciones científicas, para evitar cualquier ingenuidad acrítica. Por otro lado, comprobamos cómo esta fenomenología, en su "herejía" hermenéutica, ${ }^{6}$ se prolonga, se realiza o acaba por constituirse ética y políticamente, es decir, desde una dimensión práctica. Lo que acabo de señalar define el gesto y la orientación de esta forma de hacer filosofía; el gesto es el de la fenomenología hermenéutica (en diálogo con las ciencias) y la orientación es su vocación práctica. Este gesto y orientación lo vemos plasmado de una manera ejemplar y paradigmática en este pequeño trabajo.

Se nos presenta como una antropología del sufrimiento que se realiza como un análisis de la experiencia del sufrimiento, en su posible diferencia con el dolor. ${ }^{7}$ La vía adecuada es la comprensión de esta experiencia humana común y universal. Ahora bien, la fenomenología no puede consistir en un análisis cerrado y recursivo, interior, de la propia experiencia; precisamos, necesariamente, la "inteligencia de los signos del sufrir": es el momento hermenéutico. Y en este salir del análisis de la propia experiencia es fundamental contar con las ciencias, en este caso con la psiquiatría, y así, aunque el objetivo no sea orientar el

${ }^{6}$ Sobre esta "herejía" de la fenomenología puede verse mi trabajo "Die hermeneutische Transformation der Phänomenologie. Paul Ricœur, à l'écoute de la phénoménologie”, en J. San Martín (ed.) Phänomenologie in Spanien, Königshausen-Neumann, Würzburg, 2005, pp. 137-156.

${ }^{7}$ Todo el texto supone una crítica, al menos un cuestionamiento, de la definición de dolor que nos ofrece la International Association for Study of Pain, para la que "el dolor es una experiencia emocional desagradable en relación con una lesión real o potencial, o descrita en estos términos". Los análisis más actuales, sobre todo los que tienen lugar en el entorno de los cuidados paliativos o en las llamadas 'unidades del dolor', amplían esta noción de dolor, coincidiendo en buena medida con las propuestas que nos encontramos en este texto. 
acto terapéutico la nosografía será en esta ocasión de especial ayuda y relevancia. Aquí vemos un magnífico ejemplo de intercambio entre la fenomenología y una ciencia constituida (la psiquiatría), un análisis de la experiencia del sufrimiento y los análisis psiquiátricos. La reflexión filosófica no pierde profundidad y fuerza, al contrario, encuentra su lugar y pertinencia.

También el análisis del sufrimiento -este pequeño texto-, es fiel reflejo de la dimensión práctica (ética y política) de la filosofía de Ricœur. Pues al comprender el sufrimiento de una forma más amplia y cabal, no podemos aceptar que la atención al sufrimiento sea tan parcial y restringida como se ha venido dando. Si el sufrimiento no es el dolor, no puede ser tratado sólo como un elemento físico-biológico, sino que requiere atender a elementos biográficos, es decir, sociales, culturales y políticos. De esta manera la fenomenología del sufrimiento alcanza una ética y política del cuidado.

Ricœur muestra, como pocos fenomenólogos, la potencia crítica misma del análisis fenomenológico. Este texto es fiel reflejo de este entrecruzamiento entre fenomenología y ética o, como estoy señalando, del alcance práctico de la fenomenología. Una fenomenología reducida al análisis de la propia experiencia, encerrada en sí misma, es vacía, y, por otro lado, una ética y política del cuidado que no tenga en cuenta esa base experiencial y humana, que la fenomenología describe y descubre, es ciega.

Al mismo tiempo que este texto refleja esta estrategia discursiva y vital entrecruzamiento entre fenomenología hermenéutica y ética-, comprobamos cómo el análisis de una experiencia concreta y delimitada -práctica clínica-terapéutica del tratamiento del dolor/sufrimiento- puede aportar luz sobre otras prácticas humanas o sobre la propia vida humana en general.

Si esto es así es porque la experiencia del sufrimiento es muy peculiar, no es una experiencia parcial que un sujeto pueda tener, como se tiene otra cosa, como algo que simplemente se posee. No es una cuestión meramente coyuntural, marca la existencia. Nuestra existencia queda marcada. Se trata de una experiencia que afecta a la totalidad de la existencia. Podemos llegar a decir que no somos sujetos que sufrimos, sino que llegamos a ser sujetos-sufrientes, somos subjetividad sufriente (y no ocasionalmente, sino constitutivamente); el sufrimiento envuelve y tiñe nuestra existencia. Nuestra existencia queda coloreada por el sufrimiento.

Ricœur nos ofrece con su precisión académica y su expresar sinuoso una nueva comprensión del sufrir que considero fundamental para la medicina y la filosofía más actual. ${ }^{8}$ Quizás la idea más llamativa es esta que acabo de seña-

\footnotetext{
${ }^{8}$ Para una antropología del sufrimiento y del dolor complementaria del enfoque ricœuriano es de especial relevancia el trabajo de David Le Breton, Anthropologie de la douleur (Éditions Métailié, Paris, 2006).
} 
lar del carácter global del sufrimiento, llegando incluso al nivel de las representaciones. Y por eso podemos hablar de un nivel hermenéutico, o de una dimensión hermenéutica fundamental, del sufrir, el cual no debe ser entendido de un modo superficial, que haría de la expresión o representación del sufrimiento el campo de juego de la interpretación. No es baladí. Es decir, al sufrimiento se expresa y se representa, y la interpretación acontece como una actividad segunda que nos permite acceder al carácter difícil y a veces insondable del sufrimiento. ${ }^{9}$ Pero, vamos más allá; si el ser humano es animal hermenéutico que se interpreta interpretando, y es al mismo tiempo animal sufriente, como acabamos de señalar, la propia actividad hermenéutica constitutiva del sujeto está marcada por el sufrimiento y la fragilidad; de ahí que podamos hablar de "heridas hermenéuticas" y que la terapia hermenéutica se desarrolle en un doble nivel, el de la expresión y el de la vivencia. ${ }^{10}$

El sufrimiento no es dolor, nos insiste Ricœur en su conferencia. No es sólo dolor. El sufrimiento accede a ese nivel existencial y representativo, alcanza el nivel de nuestra propia identidad, de nuestro imaginario personal. Cuando sufro yo, sufre también la idea que de mí tengo. Mi identidad se resiente, mi biografía entra en peligro. No hay dolor que no acceda a la dimensión biográfica; el dolor vivido es sufrimiento y es un componente esencial de nuestra biografía. No podemos olvidar que el sufrimiento es el reverso, el otro lado, la otra cara de la moneda, del poder y de la experiencia de capacidad. Podríamos decir que el poder lleva aparejado no-poder, sufrimiento, como el mismo dolorsufrimiento lleva aparejado la sensación de bienestar, de poder, de capacidad. El sufrir es indicio de mis capacidades (aunque sea en ausencia) y mis capacidades ejercidas son indicio de su posible ausencia, de mi sufrir -de ahí que el temer sufrir sea ya sufrir-. Por eso una filosofía de las capacidades consecuente es al mismo tiempo una filosofía del sufrimiento, de las fragilidades y de la vulnerabilidad. ${ }^{11}$

Ricœur no dejará de decir en su antropología hermenéutica, así lo vemos en Sí mismo como otro, que somos "agentes y sufrientes". La capacidad (poder)

${ }^{9}$ Frente a una concepción del sufrir puro y mudo; vemos cómo el sufrimiento también habla, grita, exclama. Cfr. F. Worms, "Souffrant, agissant et vivant”, en C. Marin, N. Zaccaï-Reyners (eds.), Souffrance et douleur. Autour de Paul Ricour, op. cit., pp. 37-45.

${ }^{10}$ El sufrimiento implica sentimiento de inutilidad y desestima, abandono de sí, cierre sobre sí mismo. Resulta muy significativo que las situaciones de exclusión social, de 'sufrimiento social', activen las mismas estructuras cerebrales implicadas en los dolores puramente físicos. Véase al respecto Naomi I. Eisenberger, "The Neural Bases of Social Pain: Evidence for Shared Representations with Physical Pain”, Psychosomatic Medicine, 74, nº 2 (marzo), 2012, pp. 126-135.

${ }^{11}$ Cfr. P. Ricœur, "Capacités personnelles et reconnaissance mutuelle", en Anthropologie philosophique. Écrits et conférences 3, Éditions du Seuil, Paris, 2013, pp. 445-452. 
y el sufrimiento define al ser humano, todos sufrimos y el sufrimiento muestra al ser humano en su dimensión más profunda y esencial. Esta fenomenología y hermenéutica del sufrir conlleva intrínsecamente una ética del cuidado de este ser que somos, capaces e incapaces, sufrientes y poderosos (felices). ${ }^{12}$ Precisamente estas pocas páginas que componen este artículo muestran a la perfección esta idea. Por eso me permito decir que este artículo es fundamental para entender la antropología de Ricœur, y también, lo que es más importante, para entender la hondura y las implicaciones de la experiencia del sufrimiento.

Así, desde este gesto y orientación, una filosofía como la de Ricœur permite entrar en diálogo productivo y enriquecedor con otros saberes y otras prácticas (no sólo teóricas o académicas). Por ejemplo, ateniéndonos al tema del sufrimiento de la enfermedad, la propuesta de Ricœur coincide plenamente, de hecho considero que la fundamenta y le ofrece una mayor amplitud y despliegue, con la propuesta que dentro de la práctica de la medicina desarrolló en los años sesenta del siglo pasado Cicely Saunders de una nueva medicina paliativa desde la noción de la noción de "sufrimiento global" (dolor físico, mental, social y espiritual).

Esta "herejía" fenomenológica (que lleva el sello hermenéutico y ético) puede ser criticable desde otras fenomenologías, pero pocas mostrarán como ella una vocación e inspiración que constituyó a la misma fenomenología en su origen: una inspiración práctica. Esta fenomenología del sufrir es muy diferente a las que nos podemos encontrar en E. Levinas o M. Henry. ${ }^{13}$ No entro ahora en su comparación -lo dejaremos para otras investigaciones-, pero la de Ricœur, sin desdeñar rigor fenomenológico, se lanza al mundo (ciencias, saberes y prácticas), toma por guía también "los signos del sufrir", y no sólo nos ayuda a comprender mejor el sufrimiento, sino que también nos da indicaciones, indirectas, para su alivio. Tal es el gesto y la orientación de esta filosofía, magistralmente expresados en este breve trabajo.

\section{ANTROPOLOGÍA Y ÉTICA HERMENÉUTICA: EL LUGAR DEL SUFRIMIENTO}

La cuestión del sufrimiento no es un tema más al que se aplica una antropología (fenomenológica y hermenéutica) ya fundada, sino que encuentra en esta experiencia un motivo de su constitución. No se trata de un rasgo más que pueda de-

${ }^{12}$ Para una ética del cuidado desde estos planteamientos véase L. Benaroyo, "Le sens de la souffrance", en C. Marin, N. Zaccaï-Reyners (eds.), Souffrance et douleur. Autour de Paul Ricoeur, op. cit., pp. 65-73.

${ }^{13}$ Para una comparación entre Levinas y Ricœur en este punto es muy interesante el trabajo de C. Sautereau, "Subjectivité et vulnérabilité chez Ricœur et Levinas “, Études Ricœuriennes / Ricour Studies, vol. 4, nº 2, 2013, pp. 8-24. 
finir al ser humano, como podemos decir de lenguaje, la cultura, o la política. Decir "sufrimiento" es decir "acción", en su modo negativo; actividad y pasividad, hacer y padecer, 'hombre capaz' y 'hombre sufriente'-vulnerable. Ricœur va a definir su antropología, su hermenéutica del sí mismo, desde un análisis de las capacidades humanas, precisamente este texto pone de relieve que el sufrimiento es otra manera, quizás más oportuna y pertinente, de acceder a esta dimensión de capacidad y poder ("yo puedo"). No deja de hablar en Sí mismo como otro de una antropología del hombre agente y sufriente. Esta antropología de las capacidades se enlaza directamente con una ética de las capacidades. ¿Qué es la ética para Ricœur? El deseo (la busca, la intención, etc.) de una vida buena, con y para los otros, en instituciones justas. Precisamente una vida realizada (buena) es una vida plena, plenitud que bien puede definirse por el ejercicio de esas capacidades constitutivas. La ética de Ricœur se nutre así de una hermenéutica del sí mismo, es decir, de una hermenéutica de las capacidades humanas las cuales son precisamente descifradas en correlación con su no-realización, y esta no realización es precisamente el sufrimiento. De ahí la centralidad de este pequeño texto para entender la filosofía de Ricœur y, sobre todo, para captar al relación entre ética y antropología.

El tema del sufrimiento, en concreto este texto, es una entrada magnífica en su antropología de las capacidades y en la ética hermenéutica del pensador francés, lo que él llama "pequeña ética". No es este el momento de exponer ni esta antropología de las capacidades ni esta ética hermenéutica, sus textos son claros y precisos y, por mi parte, he realizado diferentes análisis a los que aquí simplemente me remito. Quiero señalar tan sólo la pertinencia y ocasión magnífica que supone el sufrimiento/dolor para adentrarnos en esta ética y antropología hermenéuticas. Antropología y ética de las capacidades se encuentran implicadas en esta reflexión sobre el sufrimiento y la fragilidad constitutiva del ser humano.

El sufrimiento es inscrito en una fenomenología de la pasividad (actividad). Estoy destacando que la centralidad de este texto sobre el sufrimiento, sin embargo, hay que decir, que su correcta comprensión requiere considerar el trabajo inicial de Ricœur sobre la voluntad, su Filosofía de la voluntad. También podemos encontrar un antecedente de este texto que comentamos en unos densos párrafos de la parte final de Sí mismo como otro $;{ }^{14}$ allí ya hablaba Ricœur del sufrimiento en el contexto de una fenomenología de la pasividad, a propósito del anclaje del sí-mismo en el cuerpo propio, y de la correlación originaria entre hacer y sufrir.

El sufrimiento es una negación de la vida, experiencia del no-ser y de la negación de la vida: "El sufrimiento es el 'no ser' sentido, antes de ser pensado",

${ }^{14}$ P. Ricœur, Soi-même comme un autre, p. 370 y ss. 
también es "una de las formas más vivas de la conciencia de sí", y más, "al sufrir, la conciencia se separa, se concentra y se conoce negada". El análisis fenomenológico es preciso y precioso, y se presta al reconocimiento de cada uno de nosotros. Sufrir implica, de alguna manera, la desaparición del mundo - del mundo como hogar- y, por eso, nos encontramos desamparados; el mundo mismo se ha convertido en 'inhóspito' (dice Ricœur en el texto). Pero también es ocasión para ser, para afirmar la propia vida y afirmarnos nosotros mismos, incluso en la propia negación que sufrimos; pero no siempre, y no siempre hasta el final. Es una experiencia de desaparición, disminución, abandono, y de ruptura del vínculo que conlleva aislamiento. Así comprendido, el sufrimiento nunca es sólo pura sensación física. Y se convierte, necesariamente, en una experiencia interrogadora y provocadora.

El sufrimiento está más allá del dolor, alcanza también la imagen de nosotros mismos, y la imagen de los otros y del mundo. Por eso supone una "coloración de existencia”. Absorbe la subjetividad. Pero, ¿se da en el sufrimiento una pura pasividad? ¿Implica una destitución del sujeto? Ricœur jugará al final del texto con esta idea para señalar la posibilidad de rastrear una hacer dentro del sufrir, acción que permite que seamos capaces de "sufrir el sufrimiento". Aguantar, sufrir, soportar... son acciones referidas al sufrir mismo. La gran pregunta es qué pasa, qué sucede, cuando esta acción de aguante y de resistencia ya no es posible. El esfuerzo del "cuidador" hacia la persona que sufre - $i$ y todos estamos en los dos lados, sufrientes y cuidadores!- apunta a buscar la resistencia del sujeto en su sufrir, ese elemento mínimo de resistencia, de actividad y de voluntad en el seno mismo del sufrir; el trabajo y la relación de cuidado (hacia otros y hacia nosotros mismos) se injertan ahí. El sufrimiento no es un puro soportar, no es una pasividad absoluta, es una resistencia activa. Ahí se ancla el cuidado.

\section{HACIA UNA ÉTICA Y POLÍTICA DEL CUIDADO}

Ricœur no quiere orientar el acto terapéutico, tan solo quiere comprender lo que sucede o puede suceder en ese acto. Ahora bien, esta comprensión lleva, aunque sea indirectamente, a una reorientación de dicho acto. Así, si el sufrimiento se comprende desde esta fenomenología del sufrir vinculado a dolor, sí, pero también más allá de él, y en relación con los otros, y con las instituciones, el cuidado (el acto terapéutico) alcanza necesariamente el nivel de una política del cuidado. En este texto encontramos recursos conceptuales para pensar el "sufrimiento social", e, incluso, el sufrimiento es global. Si el sufrimiento es también social-global, el acto terapéutico, pedirá su prolongación en una ética del cuidado así como en una política. Vemos como este planteamiento, descriptivo 
- lleno de prudencia y modestia- toca de lleno nuestro sistema sanitario, por ejemplo en lo que respecta a los cuidados paliativos, y se extiende a un nivel socio-político.

El cuidado no es una acción meramente técnica, que corresponda a unos profesionales sanitarios que curen (y no cuiden), sino que es una práctica social plural compleja. Hemos de pensar en lo que ocurre normalmente: personas (pacientes) cuyo dolor es tratado, pero el malestar y el sufrir permanecen, sin saber definirlo muy bien, pues les afecta globalmente; y así se ven abocadas -nos vemos abocados-, por ejemplo, a recurrir a medicinas poco fiables, experiencias vulgarizadas, tratamientos sospechosos o, a veces, a una lógica de la automedicación, muy peligrosa, que tiene lugar precisamente cuando se restringe el sufrimiento al "puro" dolor, el cuidado a pura curación técnico-fisiológica.

Por eso creo que sin querer orientar el acto terapéutico, este trabajo de Ricœur lo reconfigura. Apunta a que sea comprendido, en esa relación médicopaciente, como una relación de confianza necesaria para que el paciente no se sienta un caso, un dossier, una entrada en un registro, y pueda llevarse a cabo una reconfiguración de capacidades. Con esta propuesta, además, se está dando sentido a la idea de "humanización de la salud" que muchas veces queda demasiado vaga y confusa.

Este tipo de cuestiones, y esta reflexión de Ricœur, alcanza sobre todo el tema del sufrimiento y del cuidado en el final de la vida, la vulnerabilidad del paciente es extrema, como lo es la de los más cercanos. Acabar con la vida para acabar con el sufrimiento es una tentación, prolongar la vida innecesariamente también lo es. Aquí el diálogo con el enfermo, si es posible, y con los familiares es más necesario que nunca sobre todo para que el propio ejercicio del cuidado no sea minado por la duda. La distinción que nos ofrece Ricœur para pensar la cuestión de la vida es sutil y delicada. Es preciso distinguir entre el paciente que aun sufriendo se encuentra de cierto "deseo de ser y esfuerzo por existir a pesar de...", que se encuentra en un sufrir-aguantar, que es activo y apunta a una perseveración en su existir, y es capaz de "sufrir el sufrimiento", y la de aquel que el sufrimiento llega a desposeerles de su propia vida, y el sufrimiento es tan sólo un soportar, pura pasividad. El cuidado al final de la vida necesariamente es muy diferente en un caso y en otro; en el primero la actividad del cuidado se engarza en ese deseo de ser y perseverar, pero en el segundo caso, aquel en que es difícil hablar de "personas que sufran su sufrimiento", la opción de dejar morir o ayudar queda éticamente abierta y plena de humanidad. ${ }^{15}$

${ }^{15}$ Cfr. P. Ricœur, “Accompagner la vie jusqu'à la mort”, Esprit, no 3-4, marzo-abril, 2006, pp. 316-320. 
Paso a señalar y resumir todo esto que Ricœur nos está dando que pensar. Del análisis del sufrimiento que se propone se deduce una ética y política del cuidado, y, claro, si el sufrimiento no es el dolor, el cuidado no puede ser definido ya sólo como curación del dolor físico-biológico, sino que tendrá que atender el sufrimiento que es biográfico, $\mathrm{y}$, desde la ética de Ricœur, el cuidado no es sólo del sí mismo, o, dicho de otra manera, el sí mismo lleva implicado a los otros, incluso las instituciones. Así una ética del cuidado que la subjetividad sufriente exige y reclama es una ética y política del cuidado. Si el sufrimiento no es sólo biológico, sino que es también biográfico, el cuidado será biográfico. Y si el sufrimiento es global, el cuidado deberá de serlo también, y si hay un sufrimiento social, también el cuidado tendrá que acoger esta dimensión, y no como un añadido, sino como algo esencial y sustancial. Incluso podríamos hablar de "cuidado hermenéutico" parejo a un "sufrimiento hermenéutico" (unas "heridas hermenéuticas"). Cuidar a la persona que sufre no es sólo atender a su dolor, sino comprender el sentido del sufrimiento en la vida concreta de cada uno. El cuidado 'paliativo' es también, necesariamente, un cuidado hermenéutico. Si hay un sufrir hermenéutico, heridas en nuestras auto-representaciones, el cuidado, el acto terapéutico deberá contar con esta comprensión hermenéutica, porque el sufrimiento no es sólo dolor (biológico) sino también biográfico.

Podemos ver en este pequeño texto de Ricœur todo un programa de investigación (y de acción); todo un programa para una ética (y política) del cuidado. Esta reflexión sobre el sufrimiento convoca a un replanteamiento de la ética médica, de la humanización de la salud, y desde ahí a niveles más amplios y generales. Es cierto que no se busca la acción terapéutica concreta, pero implica replantear la relación de cuidados y la práctica médica; y al cuestionar el objetivismo del dolor, y reivindicar su subjetivización, ${ }^{16}$ se rompe un planteamiento estrechamente biológico. Si yo no "tengo" un cuerpo que sufre (y que puede), sino que "soy" un cuerpo (que sufre y que puede), y éste es configurado también social y culturalmente en relación con los otros, entonces cuidar "mi cuerpo" es cuidar este todo complejo.

Si dejamos de reducir, simplificar el dolor, y lo ampliamos a la esfera del sufrir, reconociendo - no olvidemos- la diferencia, nuestras instituciones deberían de cambiar. El sufrir no se debe comprender sólo en entornos de salud (médicos, asistenciales); hay un sufrir en las relaciones con los otros, en el educar, en la política, en el ejercicio de la justicia, etc. El corazón de la experiencia ética es esta experiencia del sufrir, dicho de manera negativa, o, dicho de

${ }^{16}$ Cfr. C. Marin, "Le visage de la souffrance", en C. Marin, N. Zaccaï-Reyners (eds.), Souffrance et douleur. Autour de Paul Ricœur, op. cit., pp. 47-53. 
manera positiva, experiencia del poder. Poder (hacer, ejercer) es el reverso del sufrir, pero una forma privilegiada para acceder al poder, a nuestras capacidades, es el momento y las ocasiones en que este poder se tambalea. Si el sufrimiento se comprende como disminución de capacidades, y estas son acciones, discursos, historias y estimaciones (poder de hacer, decir, narrar, y estimar) siguiendo la antropología ricœuriana- la tarea del cuidado consistirá en restablecer estos poderes.

La subjetividad-capaz es subjetividad-sufriente, si somos herida viva la labor ética y política tendrá que ser viva. La tarea desde la reflexión filosófica es responder vivamente. Precisamos una filosofía viva (hermenéutica, fenomenología... o cualquier otro nombre, no es lo importante). Ricœur habló mucho y bien a mediados de los años setenta del siglo pasado de "metáfora viva", como aquella metáfora capaz de decir la realidad viva, emergiendo, creativamente, respondiendo a una realidad viva; quizás la herida viva que somos requiere también una filosofía viva, un hacer vivo. El texto de Ricœur es una invitación a esta tarea de vitalidad, de resistencia y de responsabilidad.

\section{CONCLUSIONES: RESISTENCIA Y PARSIMONIA}

La última parte del artículo es realmente significativa y valiosa tanto desde un punto de vista de contenido como metodológico. Ricœur quiere huir, como en tantas ocasiones, del sentimentalismo y del angelismo (o dolorismo en este caso). Se distanciará de una gran tradición que quiere ver en el sufrimiento una enseñanza y un aprendizaje para la vida, tradición de corte estoico, Ricœur preferirá la tradición spinozista. ${ }^{17}$ El sufrimiento no enseña, pero sí interroga, nos pide un pensamiento distinto, vivo señalaba yo anteriormente, y nos apela, nos llama, a una acción o, al menos a un cambio de actitud.

El sufrimiento y su cuidado afecta a los procesos de subjetivización, de configuración de identidad. El sufrimiento es indicativo de que nuestra identidad puede resquebrajarse, puede desconfigurarse. Las ayudas en esos procesos de reconfiguración serán esenciales. Ni el individuo dejado a sí mismo tendrá cuidado-curación, o lo tendrá muy difícil, pero tampoco la actitud del cuidador, la atención al que sufre, puede ser total y asfixiante. Se precisa, nos recuerda Ricœur como tantas veces en su filosofía, una justa distancia, ${ }^{18}$ un cuidado justo,

${ }^{17}$ Spinoza rezuma en toda la filosofía hermenéutica de Paul Ricoeur. Probablemente sea el filósofo menos citado por él y, sin embargo, uno de los más decisivos en su pensamiento, como muestra su ética, y en concreto este texto que comentamos.

${ }^{18}$ A propósito de la relación entre amor y justicia es donde esta idea de "justa distancia" ha quedado mejor recogida y expresada. Cfr. P. Ricœur, Amor y justicia, traducción, introducción y notas de T. Domingo Moratalla, Trotta, Madrid, 2011. 
una necesaria parsimonia, es decir, circunspección y tacto. Es el propio sujeto sufriente el que ha de configurar (y reconfigurar) su vida con la ayuda -desde la ayuda- de los otros, de nuestra ayuda, pero nunca puede ser desplazado ni suplantado ni desterrado en esa tarea de aguantar el sufrimiento, de vivir en el sufrir.

Nuestros sistemas de cuidado, podemos pensar en nuestros hospitales, incentivan relaciones humanas de atención que pueden ser de poca ayuda en esta tarea, pues olvidan que se trata de individuos -cualquier de nosotros- frágiles y vulnerables. La rutina, la repetición de protocolos, la búsqueda de la eficiencia, pueden conducir a una indiferencia y banalización del sufrimiento, la cual no sólo lo disminuye, sino que lo aumenta. Para evitar esta actitud precisamos constantes tarea de educación o de sensibilización. No podemos dejar de "ponernos en la piel del otro", y más en una experiencia tan universal. Para la educación en la empatía del sufrimiento la narración se nos presenta como un instrumento ineludible. El ejercicio narrativo, tanto de escritura como de lectura (o visionado) es una forma de aprender a ampliar nuestra experiencia, hacer nuestras las experiencias de los otros. ${ }^{19}$ Frente al sufrimiento al ejercicio de la compasión alimentado por la narración, sabiendo -como bien nos recuerda Ricœur en el texto- el carácter individualizante del sufrimiento, por lo que nadie puede sufrir por otro. De ahí la parsimonia, o la distancia en el cuidado, para evitar pretensiones infundadas.

¿Qué hacer? ¿Qué cauces y posibilidades se abren para esta ética-política del cuidado? No pensemos en la gran ética (heroicidades) ni en la gran política (el Estado), pensemos en el gesto cotidiano. Si el sufrimiento se da en nuestro entorno, y Ricœur nos invita a que nos veamos como sufridores y productores de sufrimiento - no lo olvidemos-, su sanación, su minoración, también se dará en esta cotidianidad, quizás en los pequeños gestos.

Esto que comento resulta muy claro en la defensa de los "gestos simples" como respuesta apropiada para ayudar al paciente a salir de su aislamiento/isla de sufrimiento; en esos momentos, en algunos casos, hay que ayudar a afrontar el "rostro terrorífico" del sufrir, y encontrar la trama, el hilo, para salir fuera del laberinto al que ciertos tipos de sufrimiento nos pueden conducir.

Con estos gestos cotidianos me refiero a lo que en otras ocasiones he llamado "banalidad del bien". Si todos somos seres vulnerables y heridos no sería mala idea buscar los elementos de alivio, de sanación o curación, en estrategias a nuestro alcance que permitan ofrecer elementos para "sufrir el sufrimiento", aguantar o soportar el sufrir, o resistir el sufrir. No hay que pensar que la res-

${ }^{19}$ Es lo que he intentado hacer por mi parte, junto con L. Feito, llegando a hablar de una "bioética narrativa”: Bioética narrativa, Escolar y Mayo, Madrid, 2013. 
puesta va a venir, o puede venir, de un dispositivo político-institucional externo, sino de aquellas medidas que cualquiera puede hacer. Así, por ejemplo, el médico puede actuar escuchando a su paciente, dejando de mirar la pantalla del ordenador; son gestos de reconocimiento. Pequeños gestos que ofrecen un tejido de resistencia frente al olvido del sufrimiento. Pero conviene, y al hilo de todo lo que hemos comentado anteriormente, no centrarnos en las relaciones terapéuticas-médicas. Con mucha facilidad, y sin forzar, podemos pensar, y precisamente desde la experiencia del sufrir como disminución de capacidades, en el cuidado de los hijos, de los mayores, el cuidado en la educación, la actividad política como actividad de cuidado, del cuidado de la ciudad, o del cuidado del medio ambiente, etc. Lo vulnerable y frágil, también nosotros mismos con el rostro (los mil rostros) del sufrimiento, somos objeto de este cuidado, de estos gestos de resistencia.

Si el sufrimiento da que pensar, también nos convoca a una práctica cotidiana, a un ejercicio de la solicitud (atención, respeto, responsabilidad, disponibilidad, etc.), pero siempre en su "justa medida", en su parsimonia.

Esta idea de parsimonia también la podemos aplicar a la hermenéutica misma que elabora Ricœur. Se trata de no correr, ir despacio en el análisis, sin aspavientos (¡ya hay muchas filosofías del aspaviento, demasiadas!) aportando luz y claridad, para mostrar qué está en juego. Y Ricœur, con su peculiar parsimonia, lanza luz sobre una experiencia particular -el sufrir- que resulta de una ganancia y un aprendizaje descomunal.

Una fenomenología de la acción, y del sufrir (es decir, de la actividad y de la pasividad) como dos caras de la misma moneda, son la base de esta antropología, la cual implica una ética (y política) del cuidado, de la resistencia, que nos permita sufrir el sufrir, también como ejercicio de la responsabilidad. Y elaborado todo ello desde una hermenéutica de la parsimonia. Parsimonia es paciencia, sosiego, tranquilidad, templanza, equilibrio, circunspección, moderación... Es decir, la "justa distancia". El sufrimiento es pasión "siempre en exceso", pero requiere que nuestra acción sea comedida, circunspecta, parsimoniosa, sobre todo cuando la dirigimos a algo que es inevitable: nuestra propia condición. Siempre seremos agentes y sufrientes. Quizás esta es la razón de ser la compasión.

En resumen, nos encontramos ante un pequeño trabajo que aborda el sufrimiento como subjetivización del dolor y, desde ahí, esboza toda una antropología del sufrir en la que el panorama de investigación que se dibuja no es el de un cuerpo anónimo doloroso sino una subjetividad encarnada que sufre -que hace, que dice, que narra y se estima a sí misma-, y ello sin ceder a la acedía, "viviendo hasta la muerte", a pesar de... todos los rostros del dolor, con resistencia, con parsimonia y con ilusión (justa). 


\section{BIBLIOGRAFÍA}

Benaroyo, L. "Le sens de la souffrance", en C. Marin, N. Zaccaï-Reyners (eds.), Souffrance et douleur. Autour de Paul Ricour, PUF, Paris, 2013, pp. 65-73.

Domingo Moratalla, T., Domingo Moratalla, A. (ed.), Bioética y hermenéutica. La ética deliberativa de Paul Riccur (Actas del Congreso Internacional, Valencia, España, febrero 2013), Editorial Hermes, Valencia, 2014.

Domingo Moratalla, T., "Die hermeneutische Transformation der Phänomenologie. Paul Ricœur, à l'écoute de la phénoménologie", en J. San Martín (ed.) Phänomenologie in Spanien, Königshausen-Neumann, Würzburg, 2005, pp. 137-156.

Domingo Moratalla, T., "Bioética y hermenéutica. La aportación de Paul Ricœur a la bioética", Veritas, vol. II, n 17, 2007, pp. 281-312.

Domingo Moratalla, T., Feito Grande, L., Bioética narrativa, Escolar y Mayo, Madrid, 2013.

Eisenberger, N. I., "The Neural Bases of Social Pain: Evidence for Shared Representations with Physical Pain”, Psychosomatic Medicine, 74, nº 2 (marzo), 2012, pp. 126-135.

Le Breton, D., Anthropologie de la douleur, Éditions Métailié, Paris, 2006.

Marin, C., Zaccaï-Reyners, N. (eds.), Souffrance et douleur. Autour de Paul Ricour, PUF, Paris, 2013.

Marin, C., "Le visage de la souffrance", en C. Marin, N. Zaccaï-Reyners (eds.), Souffrance et douleur. Autour de Paul Ricour, PUF, Paris, 2013, pp. 47-53.

Mino, J. C., Hors de moi, Allia, Paris, 2008.

Mino, J. C., Violences de la maladie, violence de la vie, Armand Colin, Paris, 2008

Mino, J. C., Worms, F. (eds), La philosophie du soin. Médecine, éthique, société, PUF, Paris, 2010).

Ricœur, P., Soi-même comme un autre, Éditions du Seuil, Paris, 1990.

Ricœur, P., “Accompagner la vie jusqu'à la mort”, Esprit, n 3-4, marzo-abril, 2006, pp. 316320.

Ricœur, P., Amor y justicia, traducción, introducción y notas de T. Domingo Moratalla, Trotta, Madrid, 2011.

Ricoeur, P., 'La souffrance n'est pas la douleur”, en C. Marin, N. Zaccaï-Reyners (eds.), Souffrance et douleur. Autour de Paul Ricœur, op. cit., pp. 13-33.

Ricœur, P., "Capacités personnelles et reconnaissance mutuelle”, en Anthropologie philosophique. Écrits et conférences 3, Éditions du Seuil, Paris, 2013, pp. 445-452.

Sautereau, "Subjectivité et vulnérabilité chez Ricœur et Levinas “, Études Ricœuriennes/Riccur Studies, vol. 4, n² 2, 2013, pp. 8-24.

Worms, F., Le moment du soin, À quoi tenons-nous?, PUF, Paris, 2010.

Worms, F., "Souffrant, agissant et vivant”, en C. Marin, N. Zaccaï-Reyners (eds.), Souffrance et douleur. Autour de Paul Ricour,

Worms, F., Le moment du soin, À quoi tenons-nous?, PUF, Paris, 2010. pp. 37-45. 